\title{
Raptors as Indicators of Environmental Change in the Scrub Habitat of Baja California Sur, Mexico
}

\author{
RICARDO RODRÍGUEZ-ESTRELLA, ${ }^{*} \ddagger$ JOSÉ ANTONIO DONÁZAR, $†$ \\ AND FERNANDO HIRALDO $\dagger$ \\ *Centro de Investigaciones Biológicas del Noroeste, División de Biología Terrestre, km 1 Carr. San Juan de la Costa, \\ La Paz 23000 B.C.S., Mexico \\ †Estación Biológica de Doñana, Avda. María Luisa s/n, Pabellón del Perú, 41013 Sevilla, Spain
}

\section{Introduction}

"Indicator" species of natural habitat quality are potentially useful tools for managers of biodiversity (Rohlf 1991). Predators are often considered indicators because they are at the top of food webs and need wide home-range areas to function. Predators play an important role in ecosystems because they can determine the community structure patterns of their prey (Menge et al. 1994). In addition, predators, including facultative scavengers, have been used as "umbrella" species in world conservation strategies because their protection may facilitate the conservation of great portions of unaltered habitats (Simberloff 1987).

Raptors, here defined to include New World vultures, Falconiformes, and Strigiformes, have been considered good indicators of habitat quality because of their sensitivity to human disturbance and environmental contamination (Newton 1979; Taylor 1984). Population declines of some raptor species indicate dysfunctional ecosystems because population dynamics of top-order predators often reflect the nature of the ecosystems they inhabit (Newton 1979; Greene 1988; Olendorff et al. 1989; Burnham et al. 1990; Terborgh 1992). Thus, it has been recommended that raptors should be included in the management and conservation plans of any region, especially for threatened habitats (Olendorff et al. 1989; Burnham et al. 1990). The use of raptors as indicator species has been particularly advocated for tropical forests (Thiollay 1989, 1996). Their role as indicators of habitat naturalness in Neotropical areas, however, remains controversial.

Raptors may benefit from some human activities (Vannini 1989; Bird et al. 1996). Some raptors may be oppor-

‡email estrella@cibnor.mx

Paper submitted January 24, 1997; revised manuscript accepted December 2, 1997. tunistic when habitat changes occur because new feeding sources and nesting structures become available (Donázar et al. 1993a). We examined how local breeding and wintering raptor populations are affected by human activities in the desert of Baja California, until recently one of the most undisturbed areas in the world. Habitat changes have occurred along the peninsula over the last 10 years, especially in the southern part of Baja California, mostly because of increasing human activity (Masey \& Palacios 1994). Because management plans for the region may include extensive land-use changes throughout Baja California (OEA-SEDESOL-INE 1993), data on the potential effects of these changes on the status and distribution of vertebrates should be considered. Because most raptors are considered sensitive species, we expected that populations of most species of raptors would be negatively affected by anthropogenic changes in the environment.

\section{Study Area}

We studied raptors in the Cape region of Baja California, Mexico (Fig. 1), from 3 to 15 December 1993 and 29 April to 9 May 1994. Topographically, the area consists of plains and small hills intersected by occasionally flooded flat streams. The elevation is from 0 to $250 \mathrm{~m}$. This zone is characterized by low precipitation (150.6 $\mathrm{mm}$ of rain annually), a winter rainy season, and an annual mean temperature between $22.1^{\circ} \mathrm{C}$ and $23.4^{\circ} \mathrm{C}$. The study area has sarcocaulescent scrub vegetation-plants with gross stems-structurally dominated by such treelike plants as the giant cardon cactus (Pachycereus pringlei, P. pecten; average height $7 \mathrm{~m}$ ), mesquite (Prosopis articulata; average height $5 \mathrm{~m}$ ), palo verde (Cercidium microphyllum; average height $5 \mathrm{~m}$ ), plum tree (Cyrtocarpa edulis; average height $6 \mathrm{~m}$ ), copal (Bursera spp.; average height $4 \mathrm{~m}$ ), and a variety of plants $1-3 \mathrm{~m}$ in height, such as the dagger cactus (Stenocereus gummosus), 


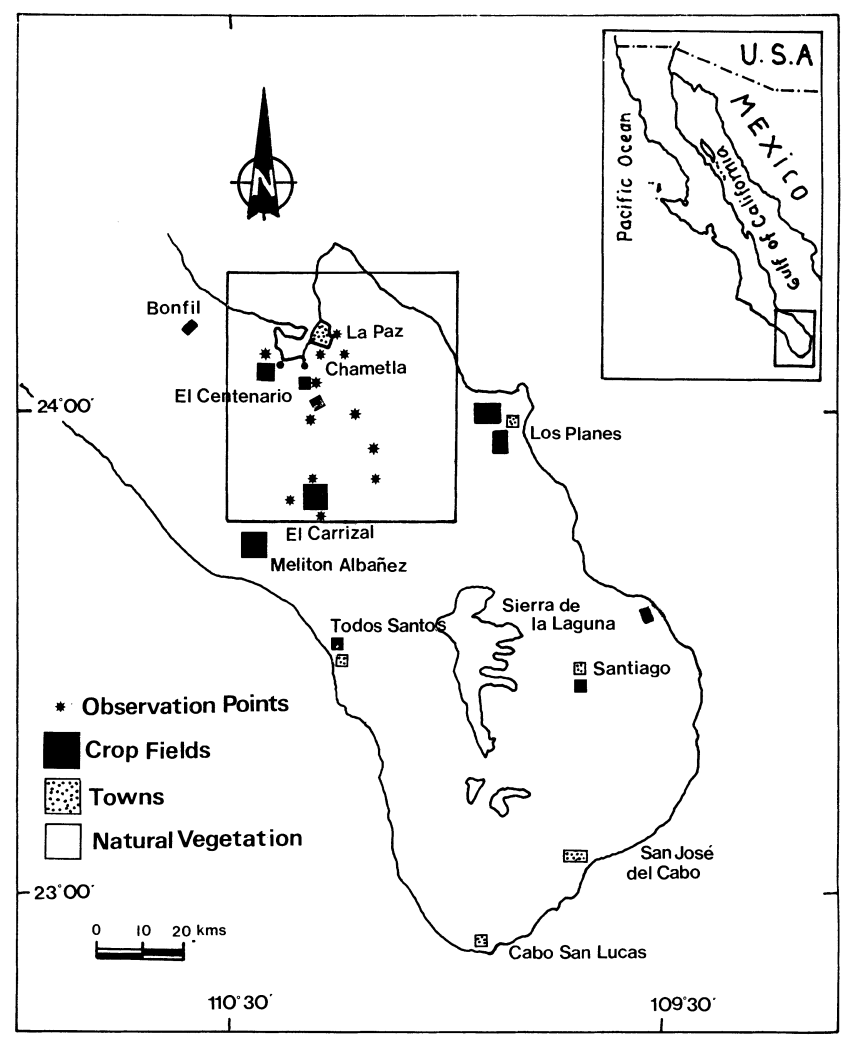

Figure 1. The Cape region of Baja California peninsula showing the patchy distribution of towns and crop fields. The study area is in the square; observation points are designated by stars. The size of towns and crop fields is not to scale, but the size of the squares represents a comparative size among them.

Adam's tree (Fouquieria diguetii), lomboy (Jatropha cinerea), and cholla (Opuntia cholla) (Wiggins 1980). Most natural vegetation in southern Baja California remains undisturbed.

Today, Baja California Sur has the lowest human density of all of Mexico (4 people $/ \mathrm{km}^{2}$; Instituto Nacional de Estadística, Geografía e Informática 1991). Small towns and ranches, mainly devoted to livestock, are sparsely distributed throughout the region (Fig. 1). Irrigated agricultural lands in southern Baja range from 4 to 20 ha and support crop fields with alfalfa, chili, vegetables, and maize. Thus, agricultural lands represent small gaps with patchy distribution in the desert scrub vegetation. La Paz, with 160,000 people, is the only large town, and Cabo San Lucas-San José del Cabo, with 18,000 people, are the only medium-sized towns. There are also several towns of fewer than 500 people. In the future, large development plans are expected because a recent law allows land acquisition by foreigners, and the Cape region has drawn the attention of developers and natural resources agencies as an economically strategic area for the State of Baja California Sur.

\section{Methods}

To determine if there were differences in the abundance and habitat use of raptors associated with human activity, we used 1:50,000 scale maps of the Instituto Nacional de Estadística, Geografía, e Informática to select observational points in the following categories: (1) areas with natural vegetation within $3 \mathrm{~km}$ of a town and not containing crop fields closer than $10 \mathrm{~km}$ from the town (TNC); (2) areas containing crop fields within $10 \mathrm{~km}$ of a town (TC); (3) crop fields surrounded by natural vegetation more than $10 \mathrm{~km}$ from a town, but small ranches could be present (NTC); and (4) areas more than $10 \mathrm{~km}$ from towns or crops with only natural vegetation (NTNC). Towns and crops in selected categories were visible from observational points. The choice of the sites for every category was made as a function of the distribution and shape of towns and crops in Baja California Sur. The distances between categories were also defined based on the wide range of foraging movements of most raptors (Newton 1979).

We selected 12 observation points in the study area, three in each of the four habitat types (Fig. 1). Four observers were involved in all observations, with each point being visited by each observer once. To estimate the use of the area by every raptor species, counts were made on four different days at each observation point. Observers visited each point either in the morning (0800-1200 hours) or the afternoon (1500-1900 hours). Every day, four single-point surveys were done in the morning and four in the afternoon. Each single-point survey lasted 3 hours, for a total of 12 hours of observation at each point. A previous test, and the respective accumulative frequency curve, proved the 3-hour sessions to be enough to record all species foraging in the area. The observer looked in a predetermined fixed direction and recorded the number of raptors sighted in a $180^{\circ}$ field of view. Only the birds perching or foraging within the fixed direction were recorded. Individuals just crossing the area for a short time were not recorded. Special attention was given to avoiding double countings when raptors were first in view and flew behind the observer to then return into view. We considered the number of contacts to be a measure of the degree of use of a habitat by raptors. Observers first scanned without binoculars and then used $10 \times$ binoculars to identify the raptors they detected. Observers were initially randomly assigned to the observation points and rotated on consecutive days until the four censuses at each point were completed. The study was conducted in December 1993 and again in May 1994 (each with 144 hours of observation), for a total of 288 hours of observation.

Analysis of variance did not detect significant differences related to observers or time of the day ( $F$ tests, $p>0.05)$ in the mean number of contacts for all raptors in the Cape region. Therefore, we pooled all data from 
observational points for every raptor species. A generalized linear model (GLM; McCullagh \& Nelder 1983; Nichols 1989) was used to determine whether species richness and the abundance of raptors were different among the four categories of human-affected areas we defined. We specifically used a GLM factorial model adjusted with the factors towns (presence-absence) and crops (presence-absence), and their interaction fitted with the program GLM (Crawley 1993). The GLMs allowed us to fit a log-linear model and permitted us to assume that the error distribution would follow a Poisson distribution and not a normal distribution because the data were counts (Donázar et al. 1993b). We used a log link for the number of species and for the number of contacts detected at each observation point (the 12 hours pooled) in both the winter and spring. The significance of each factor (towns, crops) and its interaction was tested by sequential elimination from the full model and by comparing the increase in scaled deviance with a chi-square distribution with one degree of freedom. When the minimum adequate model showed overdispersion (ratio of residual deviance to degrees of freedom is greater than one; Crawley 1993), we scaled the deviance of the model by dividing the model deviance by the Pearson chi-square. Each interaction or factor was eliminated from the model in turn. The one that produced the smallest nonsignificant increase in deviance was eliminated, and the procedure was repeated until the in- teraction or factors in the model produced a significant increase in deviance when eliminated.

We used a repeated-measures analysis of variance (SAS Institute 1985; Potvin et al. 1990) to determine whether every raptor species was differentially using the four categories of human-affected areas. Raptor species were considered in repeated measures as the subject for the four habitat types (TNC, TC, NTC, NTNC). Twelve measures ( 4 observers $\times 3$ observation points) per habitat type were used. Analyses were performed also including the season as a factor (spring, winter). We did not include in the analyses raptors with less than five contacts.

\section{Results}

We detected 8 species of raptors during the spring and 12 during the winter (Table 1 ). Only 4 nonresident species overwintered in the area (Northern Harrier, Circus cyaneus; Sharp-shinned Hawk, Accipiter striatus; Cooper's Hawk, Accipiter cooperi; and Merlin, Falco columbarius). The number of contacts in winter versus spring also suggests that the resident populations of Turkey Vultures $(\mathrm{Ca}$ thartes aura), American Kestrels (Falco sparverius), Peregrine Falcons (F. peregrinus), and Red-tailed Hawks (Buteo jamaicensis) were bolstered by migrants from the north.

Species richness did not differ among points in spring or winter. Species richness in spring was not significantly

Table 1. Mean number of contacts $( \pm \mathrm{SE})$ per habitat type of raptors in the winter and spring of 1993-1994 in the Cape region, Baja, California. ${ }^{a}$

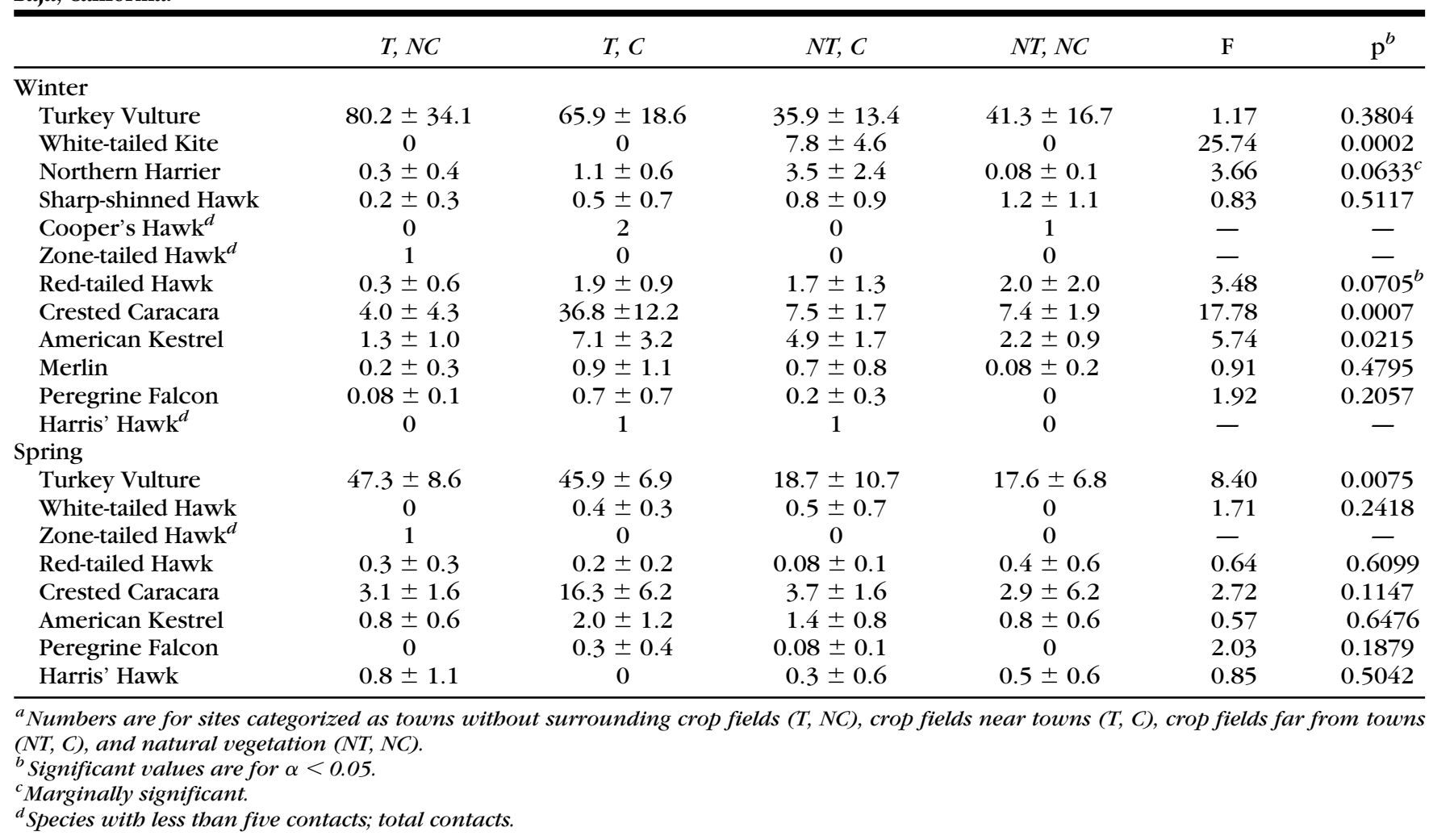


affected by towns (increase in deviance [ID] $=0.286$ ), crop fields (ID $=0.071$ ), or winter (towns, ID =0.297; crop fields, ID = 2.095). Raptor abundance, however, was higher near towns in both spring and winter (spring: towns, $F_{1,10}=42.03, p<0.001$; crop fields, $F_{1,10}=$ $1.349, p>0.05$; winter: towns, $F_{1,10}=6.459, p<0.05$; crop fields, $F_{1,10}=0.441, p>0.05$; models scaled because of significant overdispersion). Most of this difference appears to be caused by Turkey Vultures, especially in spring. When Turkey Vultures were eliminated from the analysis, the spring abundance of raptors was not affected by towns or crop fields. In the winter the number of contacts of all species was higher only in the proximity of crops (spring: towns, $F_{1,10}=2.74, p>0.05$; crop fields, $F_{1,10}=3.901, p>0.05$; winter: towns, $F_{1,10}=$ 14.65, $p>0.05$; crop fields, $F_{1,10}=48.22, p<0.001$; models scaled because of significant overdispersion).

Only Turkey Vultures used the four categories of human-affected areas differently in the spring (Table 1). In the winter, the Crested Caracara (Caracara plancus), American Kestrel, Red-tailed Hawk, White-tailed Kite (Elanus leucurus), and Northern Harrier used the human-affected areas differently (Table 1).

Turkey Vultures (both seasons) and Harris' Hawks (Parabuteo unicinctus; in spring) were seen near towns more frequently than expected, although this was significant only for Turkey Vultures in spring. Red-tailed Hawks avoided towns (marginally significant, Table 1). Most species used the town-no crop category less frequently than the other habitat types, especially strictly migrant species (Table 1).

The Crested Caracara and American Kestrel hunted preferentially over crops associated with towns in the winter season. Turkey Vultures, Northern Harriers, and Harris' Hawks were recorded less frequently in this habitat (Table 1).

The Northern Harrier and the White-tailed Kite reached the highest average number of contacts during winter in the crops-away-from-town category (Table 1). Northern Harriers used alfalfa and maize crops, and White-tailed Kites used chili, alfalfa, tomato, and maize crops.

Sharp-shinned Hawks used the natural habitat type (NTNC) more frequently, although not significantly (Table 1). Red-tailed Hawks in winter used this category more than expected (marginally significant, Table 1).

\section{Discussion}

Raptors appeared not to be good indicators of environmental change in this scrub habitat because they readily adapted to human-modified habitats. Neither raptor species richness nor raptor diversity had clear patterns of distribution related to habitat transformations in Baja California. In fact, the lowest raptor abundance was detected on the natural sarcocaulescent scrub vegetation, presumably because it lacked the open habitats favored by some species for foraging. The Turkey Vulture seemed to be the species most favored by the changes in the desert of Baja, particularly by the increasing growth of small towns. This has been reported for vultures in many other areas (Wilbur \& Jackson 1983; Donázar 1992).

The highest densities of raptors in Baja seemed to occur in fragmented habitats with gaps containing crop fields. Those areas near towns and with crop fields attracted a high number of Crested Caracaras, American Kestrels, and Peregrine Falcons during the breeding season. In zones where they are not disturbed, Crested Caracaras are known to be associated with centers of human activity such as slaughterhouses, henhouses, and garbage sites (Rodríguez-Estrella 1996). They feed on carrion and on invertebrates and vertebrates (RodríguezEstrella \& Rivera 1997). The Crested Caracara takes advantage of areas combining human settlements and crop fields. Cultivated areas are of singular importance to the recent range expansion of, for example, the White-tailed Kite in Baja California (Rodríguez-Estrella et al. 1995).

Our results show that the populations of most raptors have not declined as a result of the small-to-moderate loss of pristine sarcocaulescent scrub in Baja California Sur. In other temperate and tropical zones of America and Europe, moderate land transformations have also induced an increase in raptor diversity and abundance (Vannini 1989; Donázar et al. 1993a). These results seem to contradict those found by Thiollay $(1989,1996)$ in tropical rainforests, where raptors were good indicators of environmental changes. Differences may be due to the fact that raptor communities in temperate regions contain more generalist species, whereas most tropical raptors are forest specialists with narrow niche breadths and have a low degree of tolerance of human-altered woodlands (Thiollay 1996).

The effects of habitat alteration may change if the size of the agricultural patches, currently at less than 10 ha, increases or if a shift in agricultural crops occurs (Erichsen et al. 1996). Currently, raptors use the unaltered adjacent areas for nesting (Rodríguez-Estrella 1996, unpublished data), exploiting opportunistically the small transformed patches of "agriculture lands" and using these patches, almost exclusively, for hunting prey. If the size of the human-altered patches increases, as is expected from agriculture and urban policies, the suitable habitat for nesting and feeding would diminish. Thus, a decline of raptor populations could occur, even for opportunistic species (Newton 1979; Donázar et al. 1993b; Vickery et al. 1994).

\section{Acknowledgments}

Special thanks are due to A. Cota for field assistance. C. Anstett and J. Bustamante provided statistical advice. S. Robinson and two anonymous reviewers made sugges- 
tions that improved the manuscript. We thank E. Glazier for editing this English language text. Support from Centro de Investigaciones Biológicas del Noroeste and from Consejo Nacional de Ciencia y Tecnología (1749P-N) (México), and a grant to R. R. E. from CSIC-España, helped us finish this work.

\section{Literature Cited}

Bird, D. M., D. Varland, and J. J. Negro, editors. 1996. Raptors in human landscapes. Academic Press, London.

Burnham, W. A., D. F. Whitacre, and J. P. Jenny. 1990. Progress report III. Maya project: use of raptors as environmental indices for design and management of protected areas and for building local capacity for conservation in Latin America. The Peregrine Fund, Boise, Idaho.

Crawley, M. J. 1993. GLIM for ecologists. Blackwell Scientific Publications, Oxford, United Kingdom.

Donázar, J. A. 1992. Muladares y basureros en la biología de la conservación de las aves en España. Ardeola 39:29-40.

Donázar, J. A., O. Ceballos, A. Travaini, and F. Hiraldo. 1993a. Roadside raptor surveys in the Argentinean Patagonia. Journal of Raptor Research 27:106-110.

Donázar, J. A., F. Hiraldo, and J. Bustamante. 1993b. Factors influencing nest site selection, breeding density and breeding success in the Bearded Vulture (Gypaetus barbatus). Journal of Applied Ecology 30:504-514.

Erichsen, A. L., S. K. Smallwood, A. M. Commandatore, B. W. Wilson, and M. D. Fry. 1996. White-tailed Kite movement and nesting patterns in an agricultural landscape. Pages $165-176$ in D. M. Bird, D. Varland, and J. J. Negro, editors. Raptors in human landscapes. Academic Press, London.

Greene, H. W. 1988. Species richness in tropical predators. Pages 259274 in F. Almeda and C. Pringle, editors. Tropical rainforests: diversity and conservation. California Academy of Science, San Francisco.

Instituto Nacional de Estadística, Geografía e Informática. 1991. Resultados definitivos. Tabulados básicos. XI Censo general de población y vivienda, 1990. Aguascalientes, México.

Masey, B. W., and E. Palacios. 1994. Avifauna of the wetlands of Baja California, Mexico: current status. Studies in Avian Biology 15:45-57.

McCullagh, P., and J. A. Nelder. 1983. Generalised linear modelling. Chapman and Hall, London.

Menge, B. A., E. L. Berlow, C. A. Blanchette, S. A. Navarrete, and S. B. Yamada. 1994. The keystone species concept: variation in interaction strength in a rocky intertidal habitat. Ecological Monographs 64:249-286.

Newton, I. 1979. Population ecology of raptors. Buteo Books, Vermillion, South Dakota.
Nichols, A. O. 1989. How to make biological surveys go further with Generalised Linear Models. Biological Conservation 50:51-75.

OEA-SEDESOL-INE. 1993. Proyecto de ordenamiento ecológico de regiones geográficas con actividades productivas prioritarias. Programa de ordenamiento ecológico para el desarrollo turístico y urbano del Municipio de Los Cabos, B.C.S. México.

Olendorff, R. S., D. D. Bibles, M. T. Dean, J. R. Haugh, and M. N. Kochert. 1989. Raptor habitat management under the U. S. Bureau of Land Management Multiple-use Mandate. Raptor Research Reports 8:1-80.

Potvin, C., M. J. Lechowicz, and S. Tardif. 1990. The statistical analysis of ecophysiological response curves obtained from experiments involving repeated measures. Ecology 71:1389-1400.

Rodríguez-Estrella, R. 1996. Response of Common Black Hawks and Crested Caracaras to human activities in Mexico. Pages 356-363 in D. M. Bird, D. Varland, and J. J. Negro, editors. Raptors in human landscapes. Academic Press, London.

Rodríguez-Estrella, R., and L. B. Rivera. 1997. Crested Caracara food habits in the Cape region of Baja California, México. Journal of Raptor Research 31:228-233.

Rodríguez-Estrella, R., J. A. Donázar, and F. Hiraldo. 1995. Additional records of White-tailed Kites in Baja California Sur, Mexico. Journal of Raptor Research 29:30-31.

Rohlf, D. J. 1991. Six biological reasons why the Endangered Species Act doesn't work-and what to do about it. Conservation Biology 5:273-282.

SAS Institute, Inc. 1985. SAS user's guide: statistics. Version 5. Cary, North Carolina.

Simberloff, D. 1987. The Spotted Owl fracas: mixing academic, applied, and political ecology. Ecology 68:766-772.

Taylor, R. J. 1984. Predation. Chapman and Hall, New York.

Terborgh, J. 1992. Maintenance of diversity in tropical forests. Biotropica 24:283-292.

Thiollay, J. M. 1989. Area requirements for the conservation of rain forest raptors and game birds in French Guiana. Conservation Biology 3:128-137.

Thiollay, J. M. 1996. Rain forest raptor communities in Sumatra: the conservation value of traditional agroforests. Pages 245-261 in D. M. Bird, D. Varland, and J. J. Negro, editors. Raptors in human landscapes. Academic Press, London.

Vannini, J. P. 1989. Neotropical raptors and deforestation: notes on diurnal raptors at Finca El Faro, Quetzaltenango, Guatemala. Journal of Raptor Research 23:27-38.

Vickery, P. D., M. L. Hunter, Jr., and S. M. Melvin. 1994. Effects of habitat area on the distribution of grassland birds in Maine. Conservation Biology 4:1087-1097.

Wiggins, I. L. 1980. Flora of Baja California. Stanford University Press, Stanford, California.

Wilbur, S. R., and J. A. Jackson, editors. 1983. Vulture biology and management. University of California Press, Berkeley.

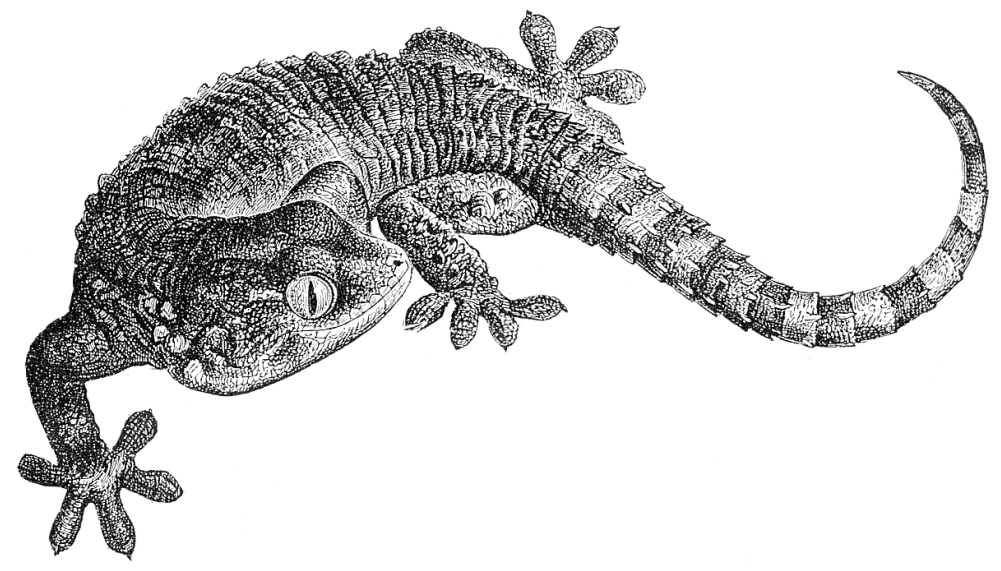

